\title{
A CASE OF XENOPHOBIA
}

\section{*Prof. Rashmi M.V.}

"Daddy, where is your carand who are all these poor people?" read a caption on a popular social networking site. Colin Saunders, a British expat working for a boutique firm Reapinvest had created uproar in one of the world's leading commercial hubs; Singapore. Reapinvest is a company which offers wealth advisory services to the rich and elite of Singapore. Colin Saunders being a wealth manager was of course wealthy and arrogant. A self-indulged Colin Saunders went onto post a picture of his son seated in a luxury car which read "Ahhhh reunited with my baby. Normal services can resume, once I have washed the stench of public transport off me". The financier was in the eye of a storm of the local Singaporeans for setting off on the wrong foot. Colin Saunders sensing the rage apologized to the local community; unfortunately, he ended up offending them more. He, in the video meant to apologize stated "Don't be angry at me, be angry with your mum and dad for raising you a wuss." This act of Colin Saunders added fuel to fire, and resulted in putting the mob to rage enough, to catch the attention of the country's Law and Foreign Affairs minister. The minister went onto comment as to how "offensive, wrong and unacceptable" the act had been. With high drama in place, Reapinvest, the company which had employed Colin Saunders, initially said the comments were made in poor taste. Subsequently, it investigated the entire fiasco and took a decision to fire him. Of course! That was meant to save the brand image of the company. The brunt was not just borne by Colin Saunders, but his family as well. In the minds of Singaporeans the word "expat" and "arrogant" go hand in hand. Native residents hurled abuses at Colin Saunders' wife and child who was just 5 years old. Colin Saunders' wife had won the title of "Miss Singapore Universe 2003". Colin Saunders had married a native Singaporean and hence held permanent residency of the country for eleven years. The locals were angry at the fact that the wife failed to comment or rectify Colin Saunders who happened to be a habitual offender of the sensibilities of people. The experience definitely traumatized the young child as well. The behavior of Colin Saunders destroyed the goodwill of the expat community. With this act of Colin Saunders the banks were under political pressure to employ more locals and the employers had to advertise the jobs locally before they could hire foreigners. The Singapore Expat Forum carried rumors of curbing job opportunities for expats. As a result of this unsavory incident, the native residents were adversely impacted and there was a fear that they would never consider the expats a part of their society. The uproar culminated into a sociopolitical and legal issue.

With friends and family backing out support, Colin Saunders, his wife and child moved to Perth, Australia following a series of life threatening calls. An expat is expected to respect

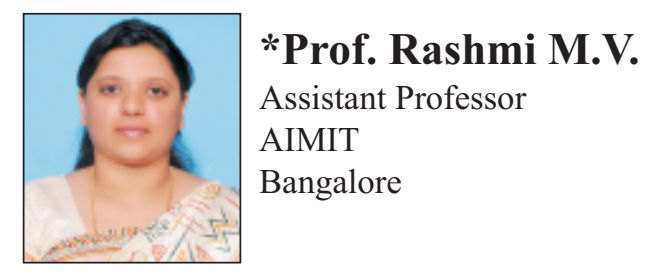


and abide by the native culture. According to Henry Chamberlain, an expert in organizational psychology, expat bankers in Asia behave this way because of the discomfort or fear they experience living in a country with different cultural values than their own. The natural biases trigger the "stranger danger" and hence people experience discomfort or disgust. Colin Saunders behavior hints at more than just cultural prejudice, they indicate an attempt to belittle those who are different from him, possibly serving to make him feel better about himself. A psychologist from
Singapore said that people sometimes get used to materialism and such people prefer to distance themselves and hence hold different values.

With an alienated life, Colin Saunders apologized again saying that he held the highest regard for the people of Singapore and that he be given another chance to rebuild the trust the people have had in him as a resident of a wonderful country.

The question that now arises is if Colin Saunders be forgiven? 